\title{
MM5 Ensemble Mean Forecasts in the Taiwan Area for the 2003 Mei-Yu Season
}

\author{
FANG-CHING CHIEN \\ Department of Earth Sciences, National Taiwan Normal University, Taipei, Taiwan \\ Yi-Chin LiU AND Ben Jong-Dao Jou \\ Department of Atmospheric Sciences, National Taiwan University, Taipei, Taiwan
}

(Manuscript received 15 September 2005, in final form 13 April 2006)

\begin{abstract}
This paper presents an evaluation study of a real-time fifth-generation Pennsylvania State UniversityNCAR Mesoscale Model (MM5) mesoscale ensemble prediction system in the Taiwan area during the 2003 mei-yu season. The ensemble system consists of 16 members that used the same nested domains of 45 - and $15-\mathrm{km}$ resolutions, but different model settings of the initial conditions (ICs), the cumulus parameterization scheme (CPS), and the microphysics scheme (MS). Verification of geopotential height, temperature, relative humidity, and winds in the $15-\mathrm{km}$ grid shows that the members using the Kain-Fritsch CPS performed better than those using the Grell CPS, and those using the Central Weather Bureau (CWB) Nonhydrostatic Forecast System (NFS) ICs fared better than those using the CWB Global Forecast System (GFS) ICs. The members applying the mixed-phase MS generally exhibited the smallest errors among the four MSs. Precipitation verification shows that the members using the Grell CPS, in general, had higher equitable threat scores (ETSs) than those using the Kain-Fritsch CPS, that the members with the GFS ICs performed better than with the NFS ICs, and that the mixed-phase and Goddard MSs gave relatively high ETSs in the rainfall simulation. The bias scores show that, overall, all 16 members underforecasted rainfall. Comparisons of the ensemble means show that, on average, an ensemble mean, no matter how many members it contains, can produce better forecasts than an individual member. Among the three possible elements (IC, CPS, and MS) that can be varied to compose an ensemble, the ensemble that contains members with all three elements varying performed the best, while that with two elements varying was second best, and that with only one varying was the worst. Furthermore, the first choice for composing an ensemble is to use perturbed ICs, followed by the perturbed CPS, and then the perturbed MS.
\end{abstract}

\section{Introduction}

The concept of ensemble forecasting originated with the work of Lorenz (1963), which documented the sensitivity of a single deterministic forecast to small uncertainties in the initial conditions. Ensemble forecasts are thus needed to predict as completely as possible the probability of future weather conditions (Epstein 1969; Leith 1974). There have been many methods proposed for creating members in an ensemble forecast by adding perturbations to the initial condition, such as the breeding of growing modes (Toth and Kalnay 1993), singular vectors (Buizza and Palmer 1995), and the Monte Carlo

Corresponding author address: Fang-Ching Chien, Dept. of Earth Sciences, National Taiwan Normal University, 88, Section 4, Ting-Chou Rd., Taipei 116, Taiwan.

E-mail: jfj@ntnu.edu.tw technique (Mullen and Baumhefner 1988; Du et al. 1997). If the model were perfect, the ensemble mean would be the best estimate of the true state of the atmosphere. However, unless a maximum dispersion between ensemble members can be reached, a general limitation of these approaches is the requirement of a large set of forecasts.

The model, however, is never perfect. Errors can also come from an imperfect representation of atmospheric processes in the model. For example, Kain and Fritsch (1992) point out that simulation results of a squall line are highly sensitive to the trigger function, an on-off switch that is used in the model to determine where and when the parameterized convection is activated. A similar conclusion is also provided by Stensrud and Fritsch (1994a,b). Wang and Seaman (1997) find that different convective parameterization schemes produce different precipitation results, and no one scheme al- 
ways outperforms the others. Therefore, it is considered to be beneficial to include the perturbed model physics, in addition to the perturbed initial conditions, in a mesoscale ensemble system (Stensrud et al. 2000; Houtekamer and Mitchell 1998; Andersson et al. 1998).

Since the early 1990s ensemble forecasting has been extensively used in operations at many forecast centers around the world, such as the National Centers for Environmental Prediction (Tracton and Kalnay 1993; Stensrud et al. 1999), the European Centre for Medium-Range Weather Forecasts (Molteni et al. 1996), the Canadian Meteorological Center (CMC; Houtekamer et al. 1996), and the Japan Meteorological Agency. In recent years, there have been many studies discussing the performance of an ensemble rainfall forecast. Many of them have shown that the average of rainfall forecasts from ensemble members provides more accurate results than a rainfall forecast from a single ensemble member (Du et al. 1997; Ebert 2001; Chien and Jou 2004). The advantages of ensemble mean forecasts are also present in predictions of other meteorological fields such as wind (Grimit and Mass 2002), temperature, moisture (Stensrud and Yussouf 2003), and so on.

Taiwan is one of the regions around the world that is frequently affected by heavy precipitation. Its complex and high-altitude terrain, which consists of steep mountain ranges such as the Central Mountain Range with peaks exceeding $3000 \mathrm{~m}$ (Figs. 1 and 2), is often a major factor in extreme rainfall events. During a mei-yu (plum rain) season, which usually occurs from mid-May to mid-June, quasi-stationary fronts (the mei-yu fronts) frequently form over southeastern China and move to the Taiwan area, resulting in extended periods of precipitation. Since the Taiwan Area Mesoscale Experiment (Kuo and Chen 1990), many studies have been performed to improve the understanding of weather systems during the mei-yu season (e.g., Chen and Hui 1990; Ray et al. 1991; Chen and Liang 1992; Lin et al. 1992; Li et al. 1997). From a numerical weather prediction (NWP) perspective, there are several models currently used in Taiwan for predicting and studying weather systems. The Central Weather Bureau (CWB) in Taiwan operates an NWP system that includes a global spectral model [the Global Forecast System (GFS); Liou et al. 1997] and a regional model [the Nonhydrostatic Forecast System (NFS); Leou and Liou 2000]. In addition, the Civil Aeronautics Administration of Taiwan, the CWB, and the National Center for Atmospheric Research (NCAR) have jointly developed a real-time mesoscale forecasting system, based
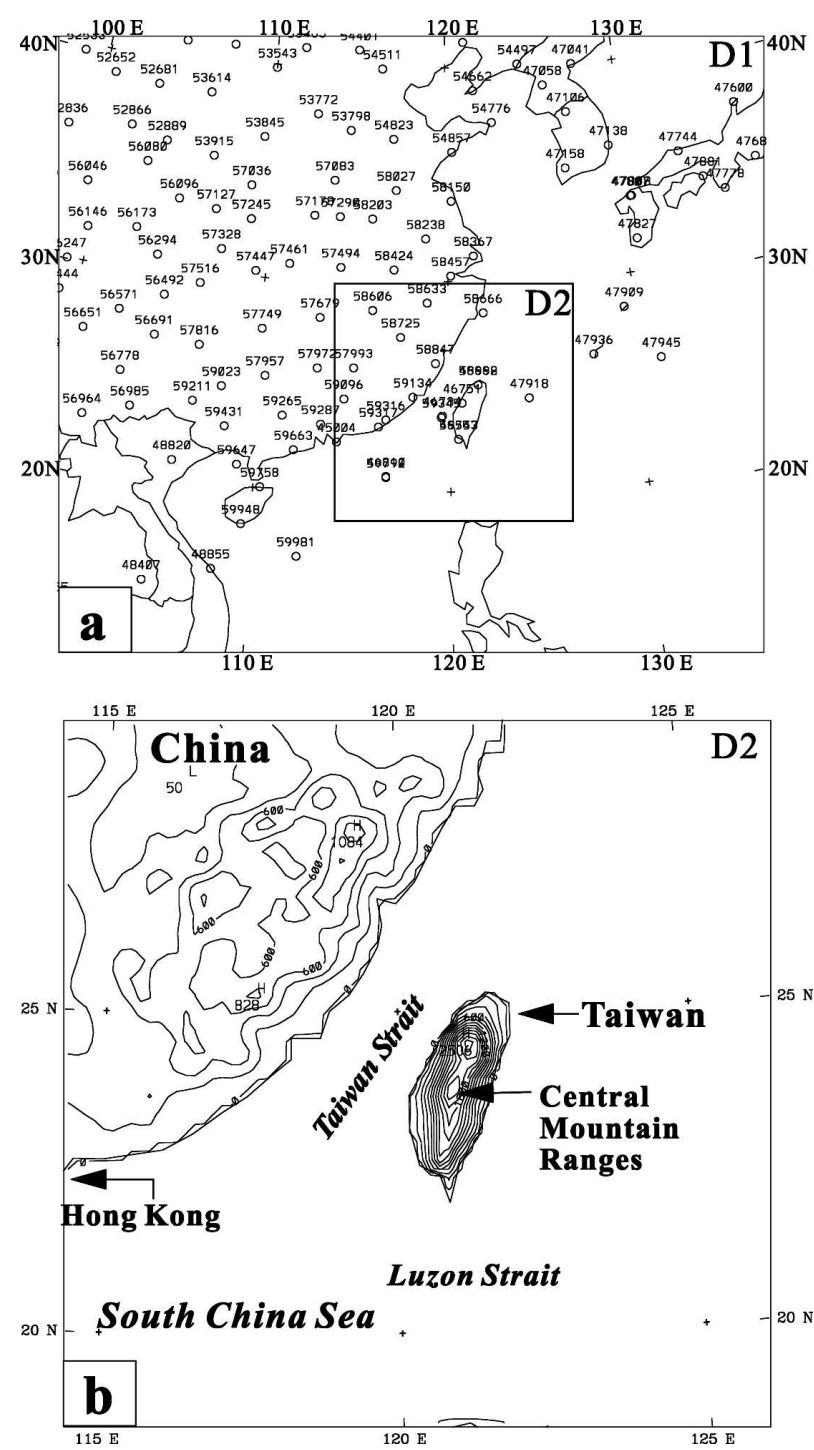

FIG. 1. (a) Domain configuration of the real-time ensemble MM5 system. The horizontal resolution is $45 \mathrm{~km}$ for domain 1 and $15 \mathrm{~km}$ for domain 2. Sounding stations are also shown. (b) Terrain height of domain 2, with a contour interval of $200 \mathrm{~m}$.

on the fifth-generation Pennsylvania State UniversityNCAR Mesoscale Model (MM5; Chien et al. 2002). Despite these observational and numerical efforts, the skill of quantitative precipitation forecasts (QPFs) in Taiwan during the mei-yu season is still very low (Chien et al. 2002). Such a forecast deficiency is partly due to the aforementioned numerical problems that are shared by many other regions of the world and partly to the unique complex and steep terrain in Taiwan that further complicates the numerical processes.

In view of the need of mesoscale ensemble precipitation forecasts, a group of researchers in Taiwan has, since 2000, jointly run an MM5 ensemble system in real 

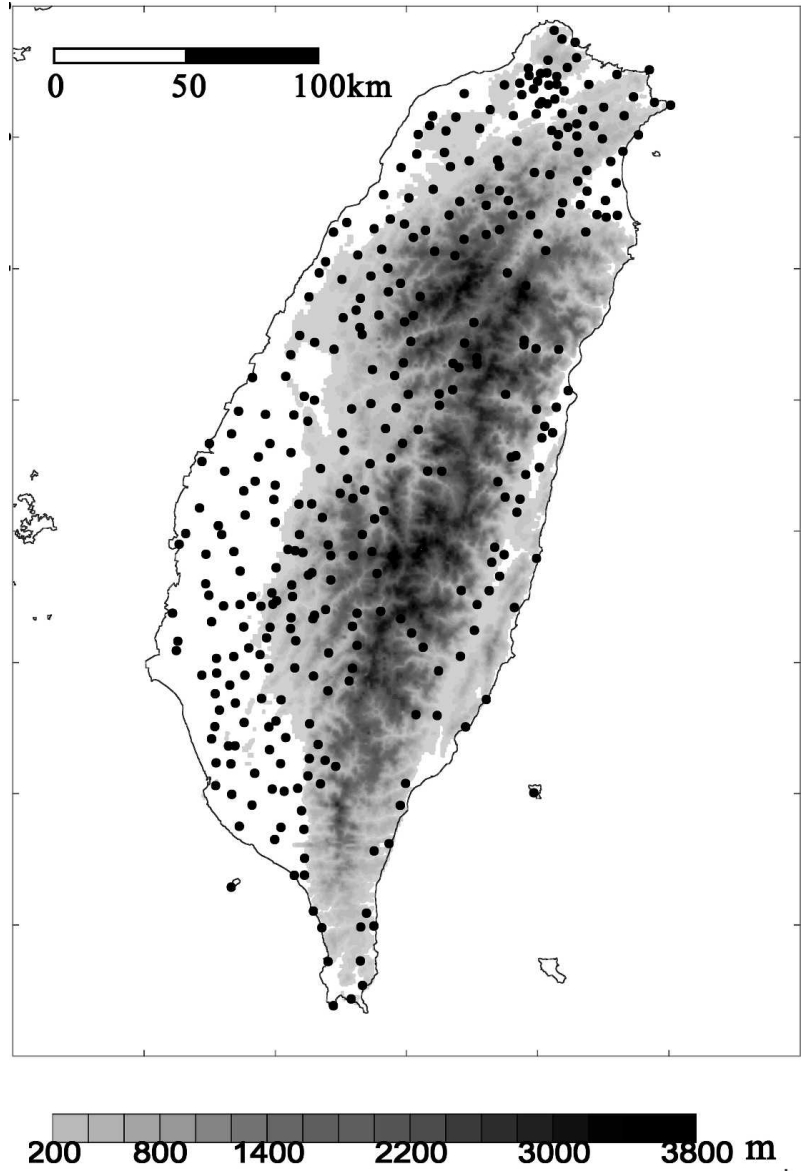

FIG. 2. The locations of the 342 rain gauge stations in Taiwan. Terrain height (shading) starts at $200 \mathrm{~m}$, with an interval of $200 \mathrm{~m}$.

time during each mei-yu season. The system consisted of six members, each run with a different combination of moist physics schemes. Chien and Jou (2004) reported the QPF verification results of this system for the 2000-02 mei-yu seasons, and found that the Grell cumulus parameterization scheme (CPS) and the Reisner I microphysics scheme (MS) performed the best among the six members. In 2003, the system was expanded to 16 members, varying among two initial conditions (ICs), two CPSs, and four MSs. Although an accurate precipitation forecast is very important for a model, the evaluation of a model is not complete if the verification of other meteorological fields such as geopotential height, temperature, relative humidity, and winds are overlooked. The purpose of this paper is thus to examine the performance of this ensemble system in terms of forecasts of precipitation and the meteorological fields during the mei-yu season of 2003. In addition, the benefit of ensemble means and the relative contribution of different IC or physics packages to the simulation are evaluated.

\section{Model configuration and verification methods}

The model configuration of each ensemble member includes two domains with $45-$ and $15-\mathrm{km}$ horizontal grid spacing, respectively (Fig. 1). The verification of this study was done in the nested domain $(15 \mathrm{~km})$. Twenty-three sigma levels were used in the vertical, with maximum resolution located in the planetary boundary layer (PBL). This relatively coarse resolution was chosen because we wanted to save time in the model simulations and the file transferring among participating institutes during the real-time experiments.

Based on the experience we had from the 2000-02 mei-yu seasons (Chien and Jou 2004), the two CPSs that performed the best in terms of QPF were selected for the ensemble system. They are the Grell and the Kain-Fritsch CPSs. The grid-resolvable explicit moisture schemes are expanded to include the mixed-phase, the Goddard, the Reisner II, and the Schultz MSs. The mixed-phase MS is just another name for the Reisner I MS that was used in Chien and Jou (2004). Please see Grell et al. (1994) for detailed descriptions of each scheme. The above physics packages were configured in a full spectrum and resulted in eight members for the ensemble system. All these members use the MediumRange Forecast model PBL parameterization (Hong and Pan 1996) to represent planetary boundary layer processes, including surface fluxes of heat, moisture, and momentum.

In addition to the perturbed physics, two different sets of initial and boundary conditions (hereafter ICs for short) were used in the ensemble system. The first set comes from the analyses and forecasts of the CWB GFS with $1^{\circ}$ resolution. This global model uses a large amount of radiance data in addition to other traditional observations during its data analysis process through a three-dimensional variational data assimilation system. The other set of ICs is obtained from the analyses and forecasts of the CWB NFS. This regional model, with 45-km resolution, uses data from the CWB GFS as firstguess fields and applies an optimum interpolation scheme to incorporate observations from the Global Telecommunications System. By adding this perturbed IC option, the ensemble system doubles its size to 16 members in all. Table 1 lists all the members and their settings, with the acronym of each member drawn from the combination of the first letters of IC, CPS, and MS. All 16 members ran twice a day at 0000 and 1200 UTC from 10 May to 20 June 2003, each run lasting for $36 \mathrm{~h}$.

In this paper, the performance of each individual member is examined in terms of forecasts of geopoten- 
TABLE 1. The ensemble members and their ICs and hydrological settings.

\begin{tabular}{rccll}
\hline \hline No. & Member* & $\begin{array}{c}\text { Initial } \\
\text { conditions } \\
\text { (ICs) }\end{array}$ & $\begin{array}{c}\text { Cumulus } \\
\text { parameterization } \\
\text { scheme (CPS) }\end{array}$ & $\begin{array}{l}\text { Microphysics } \\
\text { scheme (MS) }\end{array}$ \\
\hline 1 & GGM & GFS & Grell & Mixed phase \\
2 & GGG & GFS & Grell & Goddard \\
3 & GGR & GFS & Grell & Reisner II \\
4 & GGS & GFS & Grell & Schultz \\
5 & GKM & GFS & Kain-Fritsch & Mixed phase \\
6 & GKG & GFS & Kain-Fritsch & Goddard \\
7 & GKR & GFS & Kain-Fritsch & Reisner II \\
8 & GKS & GFS & Kain-Fritsch & Schultz \\
9 & NGM & NFS & Grell & Mixed phase \\
10 & NGG & NFS & Grell & Goddard \\
11 & NGR & NFS & Grell & Reisner II \\
12 & NGS & NFS & Grell & Schultz \\
13 & NKM & NFS & Kain-Fritsch & Mixed phase \\
14 & NKG & NFS & Kain-Fritsch & Goddard \\
15 & NKR & NFS & Kain-Fritsch & Reisner II \\
16 & NKS & NFS & Kain-Fritsch & Schultz \\
\hline
\end{tabular}

* Member acronyms drawn from the combination of the first letters of the ICs, CPS, and MS used.

tial height, temperature, humidity, winds, and rain. In addition, we intend to study the benefits of ensemble forecasts by comparing 13 ensemble mean forecasts, which are produced by simply averaging model results from particular combinations of members. The number of members in the mean ranges from 4 to 16 , grouped by the ICs or physics employed (Table 2). The naming method is similar to Table 1 except that the letter $\mathrm{E}$ is used to replace a column when all possible members corresponding to that column are used in the ensemble mean, and a numerical suffix denotes the number of members. For example, GGE4 is a 4-member ensemble mean of GGM, GGG, GGR, and GGS, and EEE16 is the ensemble mean of all 16 members.

For meteorological fields such as geopotential height $H$, temperature $T$, relative humidity $(\mathrm{RH})$, wind speed (WS), and wind direction (WD), the model is evaluated at all grid points of domain $2(15 \mathrm{~km})$. These five meteorological variables together are referred to as HTRW for short hereafter. The presumed true state used for verification is obtained from the best analyses using little-r, an objective analysis package of the MM5 based on successive correction (i.e., the Cressman scheme). The analyses of the CWB GFS are interpo-
TABLE 2. The ensemble means and the model settings of the members that are used in the mean. The naming convention is similar to that used in Table 1 except that the letter $E$ is used to replace a column when all possible members corresponding to that column are used in the mean, and a numerical suffix denotes the number of members.

\begin{tabular}{rllll}
\hline & & \multicolumn{2}{c}{$\begin{array}{r}\text { Model settings of the members that } \\
\text { are used in the mean }\end{array}$} \\
\cline { 3 - 5 } No. & Name & \multicolumn{2}{c}{ ICs } & \multicolumn{1}{c}{ CPS } \\
\hline 1 & GGE4 & GFS & Grell & All four MSs \\
2 & GKE4 & GFS & Kain-Fritsch & All four MSs \\
3 & NGE4 & NFS & Grell & All four MSs \\
4 & NKE4 & NFS & Kain-Fritsch & All four MSs \\
5 & EEM4 & All two ICs & All two CPSs & Mixed-phase \\
6 & EEG4 & All two ICs & All two CPSs & Goddard \\
7 & EER4 & All two ICs & All two CPSs & Reisner II \\
8 & EES4 & All two ICs & All two CPSs & Schultz \\
9 & EGE8 & All two ICs & Grell & All four MSs \\
10 & EKE8 & All two ICs & Kain-Fritsch & All four MSs \\
11 & GEE8 & GFS & All two CPSs & All four MSs \\
12 & NEE8 & NFS & All two CPSs & All four MSs \\
13 & EEE16 & All two ICs & All two CPSs & All four MSs \\
\hline
\end{tabular}

lated to the MM5 grid as the first guess and then the little-r is applied to incorporate upper-air and surface observations. We chose three scalar measures of forecast accuracy for the HTRW fields. First, a root-meansquare error (RMSE) is defined by

$$
\text { RMSE }=\sqrt{\frac{\sum_{n=1, N}\left(F_{n}-O_{n}\right)^{2}}{N-1}},
$$

where $F_{n}$ denotes the forecasted fields, $O_{n}$ represents the observations (or the analyses), and $N$ is the sample size. Wind direction differences are constrained to have a maximum of $180^{\circ}$, with positive (negative) biases representing a clockwise (counterclockwise) forecast error. The mean error (ME), defined as

$$
\mathrm{ME}=\frac{\sum_{n=1, N}\left(F_{n}-O_{n}\right)}{N},
$$

is also computed in order to evaluate the model bias. Last, we calculate the correlation coefficient (CC) between the forecasted and observed variables by

$$
\mathrm{CC}=\frac{\frac{1}{N-1} \sum_{n=1, N}\left[\left(F_{n}-\bar{F}\right)\left(O_{n}-\bar{O}\right)\right]}{\left[\frac{1}{N-1} \sum_{n=1, N}\left(F_{n}-\bar{F}\right)^{2}\right]^{1 / 2}\left[\frac{1}{N-1} \sum_{n=1, N}\left(O_{n}-\bar{O}\right)^{2}\right]^{1 / 2}}
$$


where an overbar denotes the mean of that variable. These three parameters are calculated for the HTRW fields at standard pressure levels and at every $12 \mathrm{~h}$ of forecast time. For brevity, only the scores at 850, 700, and $500 \mathrm{hPa}$ and at $24 \mathrm{~h}$ of model forecasts are presented here.

Precipitation forecasts of the nested domain $(15 \mathrm{~km})$ are verified at the grid points over land in Taiwan for two forecast periods, including 12-24 and 24-36 h. For brevity, only results of the 12-24-h forecasts are presented. For the performance of the 24-36-h precipitation forecasts, the verification performed by Chien and Jou (2004) is recommended for reference. Observations from the 342 rain gauge stations in Taiwan (see Fig. 2) are used for verification. Data from the rain gauges located within a $15-\mathrm{km}$ square, centered at a grid point of the $15-\mathrm{km}$ domain, were averaged to represent the observed rainfall amount at that grid point. These processed data were then compared with the model precipitation amount at the same grid point and over the same time period. The result was used as a sample for verification. Because there were 141 grid points over the land area of Taiwan in the $15-\mathrm{km}$ domain, each MM5 run would create at most 141 samples for a specified time interval. In some cases, fewer samples were obtained because of missing observational data or low rain gauge density over a certain region of the domain (particularly over high mountains and over eastern Taiwan).

We used equitable threat scores (ETS; see Schaefer 1990) and bias scores to verify the precipitation forecast of the ensemble system. The definition of ETS was the same as the standard threat score except that the expected number of hits ${ }^{1}$ in a random forecast $R$ is subtracted from both the numerator $(H)$ and the denominator $(F+O-H)$ :

$$
\mathrm{ETS}=\frac{H-R}{F+O-H-R},
$$

where $H$ is the number of hits and $F$ and $O$ are the numbers of samples in which the precipitation amounts are greater than the specified threshold in the forecast and the observation, respectively. The random forecast is $R=F O / N$, where $N$ is the number of points being verified. The thresholds used in this study included 2.5, 10 , and $25 \mathrm{~mm}$ of precipitation. The bias scores were calculated by

$$
\text { bias }=\frac{F}{O} \text {. }
$$

\footnotetext{
${ }^{1} \mathrm{~A}$ hit is represented by both the observed and forecasted rainfall amounts greater than a specified threshold.
}

\section{Verification of the HTRW fields}

The verification of the HTRW fields was done at all grid points (6084 points) of domain 2 for 84 runs. The sample size $N$ thus is approximately 500000 for each evaluation.

\section{a. Individual members}

Figures 3 and 4 show the RMSE and ME of the HTRW fields at 850,700 , and $500 \mathrm{hPa}$ for all individual members at $24 \mathrm{~h}$ into the simulation. A quick glance at Fig. 3 shows that different CPSs appear to have the greatest effect on the scores of nearly all variables; that is, the members that used the Kain-Fritsch CPS (members 5-8 and 13-16) mostly had lower RMSEs than those using the Grell CPS (members 1-4 and 9-12). An exception to this was the forecast of geopotential height at $500 \mathrm{hPa}$. For geopotential height prediction, the NKM (member 13, which used the NFS ICs, the KainFritsch CPS, and the mixed-phase MS) had the lowest RMSEs among the 16 members at 850 and $700 \mathrm{hPa}$. Also, the members that used the mixed-phase MS exhibited the smallest RMSEs among the four MSs when the same IC and CPS were applied. It is therefore suggested that the mixed-phase MS was the best option among the four MSs when geopotential height accuracy is a concern. The above findings could also be obtained in the mean error distribution of geopotential height (Fig. 4). In addition, it is found that the model, regardless of which ICs or physics were used, tended to overpredict height, especially at $850 \mathrm{hPa}$.

The RMSEs of temperature forecasts also showed that the Kain-Fritsch CPS members performed better than the Grell CPS members, with the difference getting smaller at higher levels (Fig. 3). In contrast to the CPSs, the choices of different MSs appeared to have very little impact on the temperature forecasts. The large RMSEs of temperature at $850 \mathrm{hPa}$ were the result of cold biases in the model (Fig. 4), which became smaller at higher levels. As for relative humidity, the RMSE also showed the advantage of using the KainFritsch CPS over the Grell CPS (Fig. 3). In addition, the members that used the NFS ICs, in general, had smaller errors than those using the GFS ICs, especially at $700 \mathrm{hPa}$. The mean error of relative humidity further indicated that the model had dry biases at $700 \mathrm{hPa}$ (Fig. 4). The Kain-Fritsch CPS resulted in dry biases at 850 $\mathrm{hPa}$, but not at $500 \mathrm{hPa}$. In contrast, the Grell CPS, which caused dry biases only at $500 \mathrm{hPa}$, had a reverse distribution.

The RMSEs of wind speed and wind direction forecasts were large at $850 \mathrm{hPa}$, probably because of influences from the boundary layer (Fig. 3). At higher lev- 


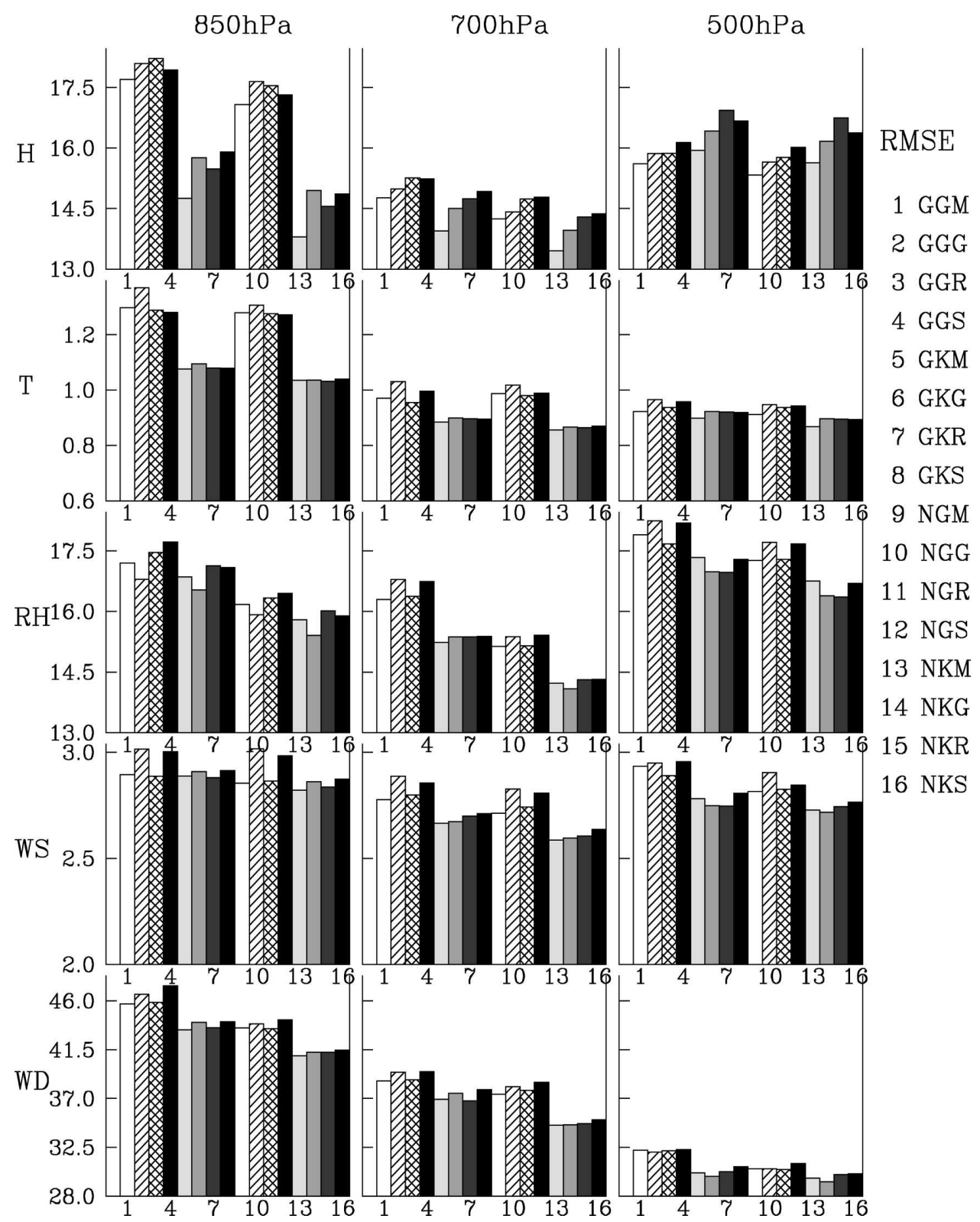

FIG. 3. RMSE of geopotential height $(H ; \mathrm{m})$, temperature $\left(T ;{ }^{\circ} \mathrm{C}\right)$, relative humidity $(\mathrm{RH} ; \%)$, wind speed (WS; $\mathrm{m} \mathrm{s}^{-1}$ ), and wind direction (WD; degrees) at 850, 700, and $500 \mathrm{hPa}$ of $\mathrm{D} 2$ for all single members at $24 \mathrm{~h}$ into the simulation.

els, it became clearer that the Kain-Fritsch CPS performed better than the Grell CPS. The mean error of wind speed showed that the error at $700 \mathrm{hPa}$ was caused by the underforecasting of the model (Fig. 4). It is thus possible to improve the skill of the $700-\mathrm{hPa}$ wind speed prediction by applying an appropriate bias correction procedure. At 850 and $500 \mathrm{hPa}$, however, although model biases were small, overall the model did not perform well for wind speed because their RMSEs were large. Wind direction forecast skill appeared to im- prove greatly from 850 to $500 \mathrm{hPa}$ because of the increasing geostrophy at higher levels. Its mean errors were relatively insignificant compared with the large RMSEs.

The above comparisons were further examined by computing the RMSE difference of the HTRW fields at three levels between pairs of members that used only one different element among the three possible elements (ICs, CPS, or MS) in the model, for example, GGM minus NGM (No. 1 - No. 9). A positive (nega- 


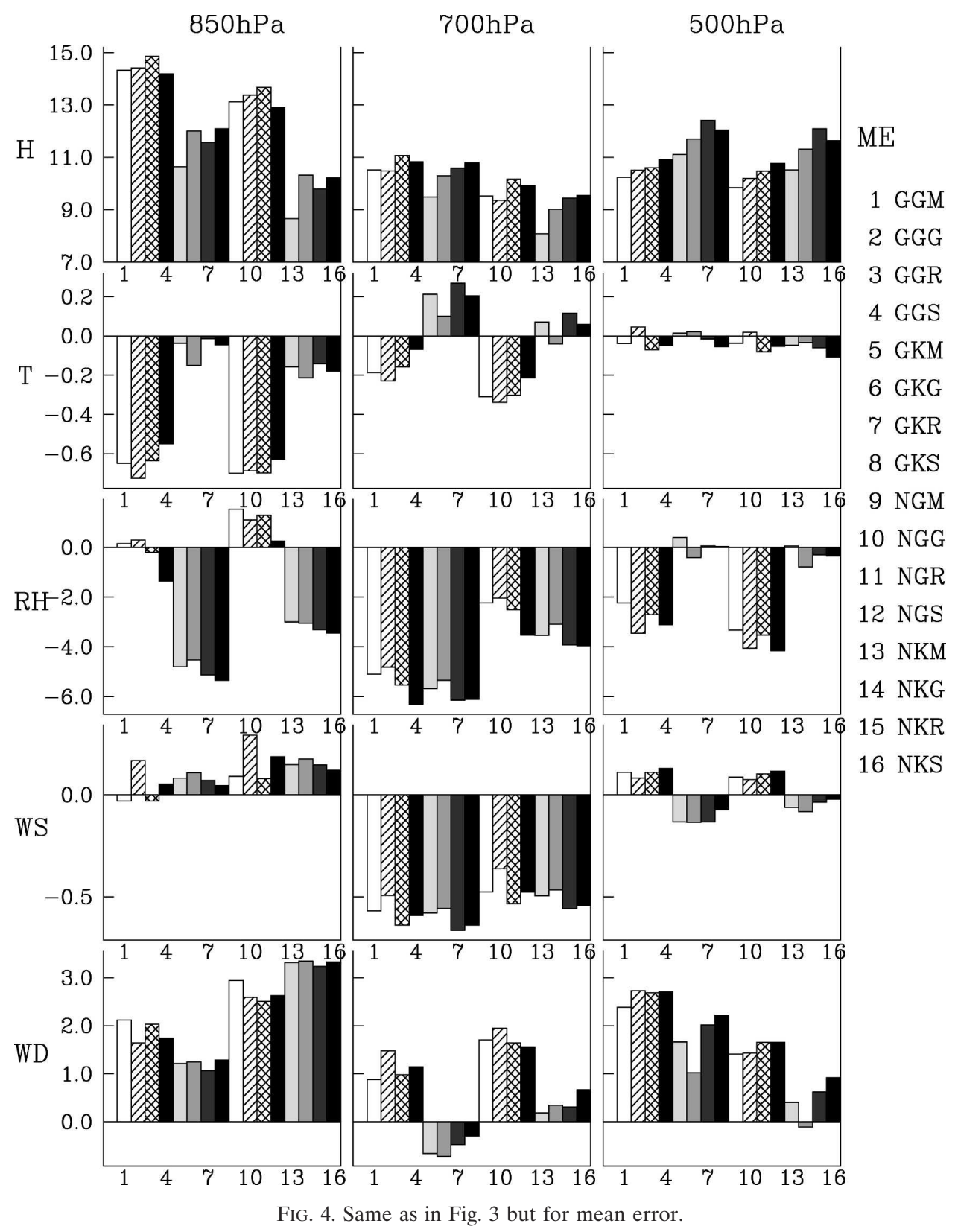

tive) value indicates that the first member (e.g., GGM) performed worse (better) than the second member (e.g., NGM). In addition, we used the resampling technique (Wilks 1995) to test whether the difference reached a significance level of $90 \%$. Table 3 shows the number of times positive or negative values occurred in a group and the number of times the differences reached the significance level. It is clear that, for the HTRW fields, almost all members using the NFS ICs performed better than those using the GFS ICs (positive differences). A similar result was found between the Kain-Fritsch and the Grell CPSs, except that the ratios of reaching the significance level were much larger for all five variables. Among the four MSs, Table 3 shows that the mixed-phase MS performed relatively the best and the Shultz MS was the worst, for forecasts of the HTRW fields. However, most of the differences were too small to reach the $90 \%$ significance level.

Figure 5 presents the $\mathrm{CC}$ of the aforementioned variables. It is found that geopotential height predictions had the highest correlation with the analyses among the five variables, especially at high levels. The CCs of all members exceeded 0.9 at $500 \mathrm{hPa}$ and were around 0.85 at $700 \mathrm{hPa}$. The differences of CCs among the members 
TABLE 3. RMSE differences of the HTRW fields ( $H, T, \mathrm{RH}, \mathrm{WS}, \mathrm{WD})$ at three levels and ETS differences of rain for three thresholds between individual members. The differences are computed in pairs of members with only one different element (IC, CPS, or MS) used in the model. See footnote for the members used and the total number of pairs in each group. The number of times positive/negative values (separated by a slash) occurred among all possible pairs in the group is shown. Numbers in parentheses denote the number of times the difference reached a statistical significance level of $90 \%$. See Table 1 for acronyms and corresponding members.

\begin{tabular}{lccccccc}
\hline \hline & Group No.* & $H$ & $T$ & RH & WS & WD & Rain \\
\hline IC (G - N) & 1 & $24(3) / 0$ & $21(1) / 3(0)$ & $24(14) / 0$ & $23(0) / 1(0)$ & $24(2) / 0$ & $16(6) / 8(0)$ \\
CPS (G - K) & 2 & $16(8) / 8(2)$ & $24(18) / 0$ & $24(12) / 0$ & $24(9) / 0$ & $24(9) / 0$ & $22(6) / 2(0)$ \\
MS (M-) & 3 & $5(0) / 31(4)$ & $19(3) / 17(2)$ & $13(0) / 23(0)$ & $12(0) / 24(0)$ & $8(0) / 28(0)$ & $24(14) / 12(3)$ \\
MS (G-) & 4 & $15(0) / 21(2)$ & $17(2) / 19(2)$ & $16(0) / 20(0)$ & $14(0) / 22(0)$ & $14(0) / 22(0)$ & $25(8) / 11(5)$ \\
MS (R-) & 5 & $23(2) / 13(2)$ & $19(0) / 17(1)$ & $19(0) / 17(0)$ & $17(0) / 19(0)$ & $18(0) / 18(0)$ & $12(5) / 24(9)$ \\
MS (S-) & 6 & $29(6) / 7(0)$ & $17(0) / 19(0)$ & $24(0) / 12(0)$ & $29(0) / 7(0)$ & $32(0) / 4(0)$ & $11(3) / 25(13)$ \\
\hline
\end{tabular}

* Pairs of members used in the corresponding group (refer to Table 1 for the member's number):

1) The GFS ICs minus NFS ICs: $1-9,2-10,3-11,4-12,5-13,6-14,7-15,8-16$ (8 pairs $\times 3$ levels/thresholds).

2) The Grell CPS minus Kain-Fritsch CPS: $1-5,2-6,3-7,4-8,9-13,10-14,11-15,12-16$ (8 pairs $\times 3$ levels/thresholds).

3) The mixed-phase MS minus any of the other three MSs: $1-2,1-3,1-4,5-6,5-7,5-8,9-10,9-11,9-12,13-14$, $13-15,13-16$ (12 pairs $\times 3$ levels/thresholds).

4) The Goddard MS minus any of the other three MSs: $2-1,2-3,2-4,6-5,6-7,6-8,10-9,10-11,10-12,14-13$, $14-15,14-16$ (12 pairs $\times 3$ levels/thresholds).

5) The Reisner II MS minus any of the other three MSs: $3-1,3-2,3-4,7-5,7-6,7-8,11-9,11-10,11-12,15-13$, $15-14,15-16$ (12 pairs $\times 3$ levels/thresholds).

6) The Schultz MS minus any of the other three MSs: $4-1,4-2,4-3,8-5,8-6,8-7,12-9,12-10,12-11,16-13$, $16-14,16-15$ (12 pairs $\times 3$ levels/thresholds).

were very small compared with those of RMSE and mean error. Even so, it is still noticed from $850 \mathrm{hPa}$ that the members using the Kain-Fritsch CPS had slightly higher CCs than those using the Grell CPS when the same ICs and MS were applied. Temperature forecasts also had high CCs $(\sim 0.8)$, but mostly at low levels such as 850 and $700 \mathrm{hPa}$. The distribution of CCs among members was generally inversely related to that of RMSE or ME; that is, the members with higher CCs had lower errors. The forecasts of relative humidity had the highest CCs at $700 \mathrm{hPa}$ and the lowest CCs at 850 $\mathrm{hPa}$. At these two levels, the advantage of using the Kain-Fritsch CPS over the Grell CPS was evident. For wind speed forecasts, the CCs increased with height, similar to the geopotential height forecasts. The CCs of wind direction forecasts were the lowest among the five variables.

\section{b. Ensemble means}

Skill comparison among different ICs, CPSs, and MSs is more easily made from the scores of ensemble mean forecasts as presented in Fig. 6, which shows the RMSEs of 13 different ensemble means described in Table 2. We also applied the same method as in Table 3 to check the differences of RMSEs and their significance levels between ensemble means. The result is shown in Table 4. It is first noted that RMSEs of these ensemble means were, in general, smaller than those of individual members in Fig. 3, indicating that the ensemble mean could more consistently provide better forecasts than individual members. The first four ensemble means, each containing four members with the same ICs and CPSs, but different MSs, represent the ensemble mean performance of their particular ICs and CPS. For example, the RMSEs of GKE4 were, in nearly all panels, smaller than those of GGE4, and a similar pattern existed between NKE4 and NGE4. This suggests that, as stated in the previous subsection, members with the Kain-Fritsch CPS (or their ensemble means), in general, performed better than those with the Grell CPS. The comparison also shows that ensemble means of the NFS members had lower RMSEs than those of the GFS members. This indicates that using data from a regional model for the initial conditions has an advantage over those from a global model in terms of forecasting height, temperature, $\mathrm{RH}$, and wind. It could be that the NFS supplied better analysis and boundary data, with a higher resolution as well, than the GFS. The above results were more evident in comparisons of the eight-member ensemble means (the 9th to the 12th) between EGE8 and EKE8, and between GEE8 and NEE8. Table 4 further shows that, for the HTRW fields, some differences could reach the $90 \%$ significance level. Given the smoothing nature of ensemble means, it is more difficult for the differences between ensemble means to reach the significance level than between individual members as shown in Table 3 .

Comparisons among the fifth to the eighth ensemble means in Fig. 6 show that the ensemble mean of the mixed-phase MS (EEM4) had the lowest RMSE when 


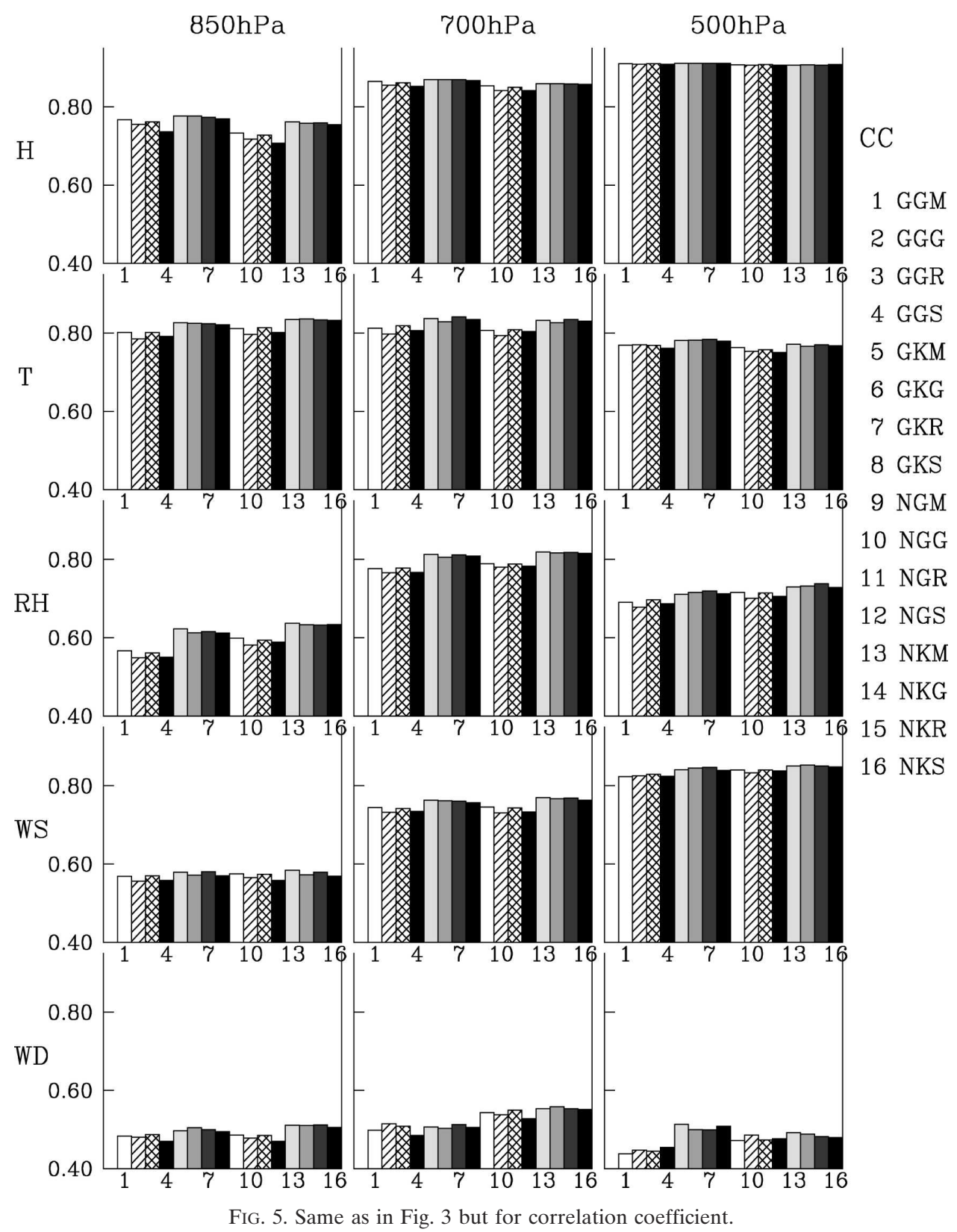

geopotential height predictions were evaluated. Forecasts of the other variables showed very small RMSE differences, but it still appears that EEM4 in general had a slight advantage over the other three ensemble means. This is clearly shown in Table 4, although most of the differences were not large enough to reach the $90 \%$ significance level. We therefore conclude that the mixed-phase MS is the best choice among the four MSs for MM5 simulation in the Taiwan area. For geopotential height forecasts, the RMSEs of the all-member ensemble mean (EEEl6) were roughly equal to the average of the RMSEs of the ensemble means that comprise all 16 members (e.g., No. 1-4, No. 11-12, etc.). For predictions of temperature, $\mathrm{RH}$, and wind, EEE16 in general had even lower RMSEs than the average. This implies that the forecast skill of an ensemble mean could be improved by including ensemble members with large diversity.

To better show the advantages and the limitations of an ensemble mean, RMSEs were ranked from the best to the worst among the 16 single members and the ensemble mean EEE16 twice daily for each of the HTRW fields at each level during the 42-day period. The number of times a single member or EEE16 performed the 


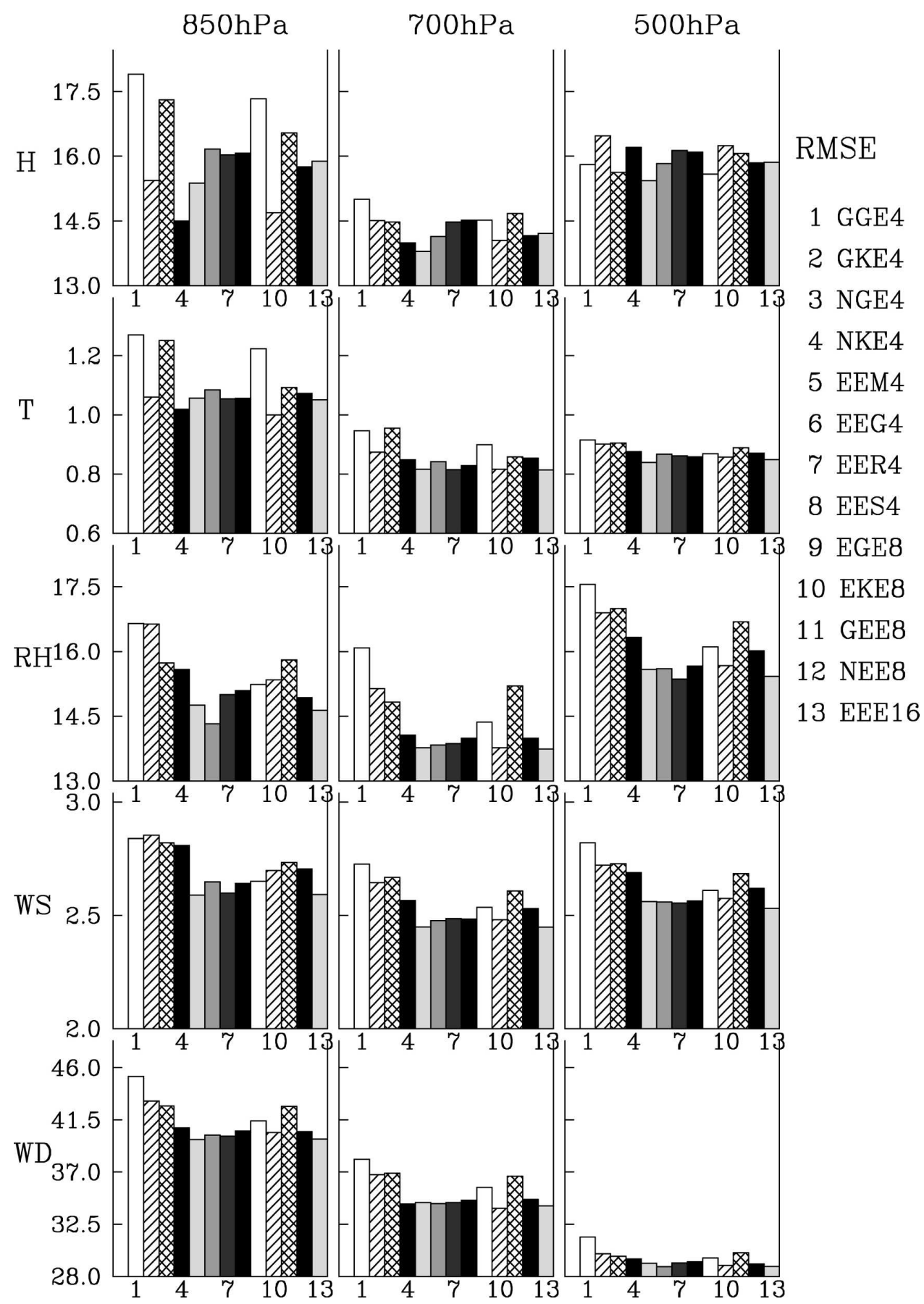

FIG. 6. Same as in Fig. 3 but for the 13 ensemble means as listed in Table 2.

best or the worst is shown in Table 5, along with its percentage out of the 1260 possible rankings. It is clear that compared with all individual members, EEE16 had the highest chance $(21 \%)$ of being the best performer in forecasting the HTRW fields, and it never finished the worst. This is really the advantage of using an ensemble mean forecast. However, the limitation is that there was still a large chance $(79 \%)$ of the ensemble mean being not the best. On this occasion, each individual member was capable of performing the best, but it could also perform the worst at some other times. Therefore, probabilistic forecasting should be considered in order to further improve an ensemble forecast. Table 5 also shows that NKM had the highest chance (12\%) of being 
TABLE 4. Same as in Table 3 but for ensemble means. See Table 2 for acronyms.

\begin{tabular}{lcllllll}
\hline \hline & Group No. & \multicolumn{1}{c}{$H$} & \multicolumn{1}{c}{$T$} & \multicolumn{1}{c}{ RH } & WS & WD & Rain \\
\hline IC (G - N) & 1 & $3(0) / 0$ & $3(0) / 0$ & $3(1) / 0$ & $3(0) / 0$ & $3(0) / 0$ & $2(2) / 1(0)$ \\
CPS (G - K) & 2 & $2(1) / 1(0)$ & $3(2) / 0$ & $2(0) / 1(0)$ & $2(0) / 1(0)$ & $3(0) / 0$ & $3(2) / 0$ \\
MS (M-) & 3 & $0 / 9(1)$ & $3(0) / 6(0)$ & $2(0) / 7(0)$ & $2(0) / 7(0)$ & $2(0) / 7(0)$ & $7(5) / 2(0)$ \\
MS (G-) & 4 & $5(1) / 4(0)$ & $9(0) / 0$ & $3(0) / 6(0)$ & $5(0) / 4(0)$ & $2(0) / 7(0)$ & $7(3) / 2(1)$ \\
MS (R-) & 5 & $6(0) / 3(0)$ & $2(0) / 7(0)$ & $4(0) / 5(0)$ & $4(0) / 5(0)$ & $5(0) / 4(0)$ & $1(1) / 8(6)$ \\
MS (S-) & 6 & $7(0) / 2(0)$ & $4(0) / 5(0)$ & $9(0) / 0$ & $7(0) / 2(0)$ & $9(0) / 0$ & $3(1) / 6(3)$ \\
\hline
\end{tabular}

* Pairs of ensemble means used in the corresponding group:

1) GEE8 - NEE8 (1 pair $\times 3$ levels/thresholds);

2) EGE8 - EKE8 (1 pair $\times 3$ levels/thresholds);

3) EEM4 - EEG4, EEM4 - EER4, and EEM4 - EES4 (3 pairs $\times 3$ levels/thresholds);

4) EEG4 - EEM4, EEG4 - EER4, and EEG4 - EES4 ( 3 pairs $\times 3$ levels/thresholds);

5) EER4 - EEM4, EER4 - EEG4, and EER4 - EES4 (3 pairs $\times 3$ levels/thresholds); and

6) EES4 - EEM4, EES4 - EEG4, and EES4 - EER4 (3 pairs $\times 3$ levels/thresholds).

the best and the lowest chance (1\%) of being the worst among the 16 single members, which is consistent with the results in the previous subsection.

\section{Verification of precipitation}

Figure 7 presents the observed 12 -h accumulated precipitation amounts averaged for all 342 rain gauge stations in Taiwan from 0000 UTC 11 May to 0000 UTC 22 June 2003. The major rainfall events of the 2003 mei-yu season included a period of light precipitation between 15 and 19 May, and a period of heavy precipitation after 6 June. The largest rainfall occurred on 7 June 2003. The simulated precipitation was verified at the Taiwan-

TABLE 5. The number of times a single member or the ensemble mean EEE16 performed the best or the worst among the 16 members and the ensemble mean in the forecasts of the HTRW fields at three levels. The comparison was made twice daily for each field at each level during the 42-day period. The percentages out of 1260 comparisons are shown in parentheses.

\begin{tabular}{rlrc}
\hline \hline No. & Name & Best & Worst \\
\hline 1 & GGM & $67(5 \%)$ & $57(5 \%)$ \\
2 & GGG & $38(3 \%)$ & $202(16 \%)$ \\
3 & GGR & $31(2 \%)$ & $83(7 \%)$ \\
4 & GGS & $22(2 \%)$ & $190(15 \%)$ \\
5 & GKM & $108(9 \%)$ & $40(3 \%)$ \\
6 & GKG & $70(6 \%)$ & $32(3 \%)$ \\
7 & GKR & $60(5 \%)$ & $67(5 \%)$ \\
8 & GKS & $36(3 \%)$ & $65(5 \%)$ \\
9 & NGM & $59(5 \%)$ & $42(3 \%)$ \\
10 & NGG & $59(5 \%)$ & $164(13 \%)$ \\
11 & NGR & $38(3 \%)$ & $46(4 \%)$ \\
12 & NGS & $23(2 \%)$ & $134(11 \%)$ \\
13 & NKM & $157(12 \%)$ & $12(1 \%)$ \\
14 & NKG & $113(9 \%)$ & $25(2 \%)$ \\
15 & NKR & $66(5 \%)$ & $56(4 \%)$ \\
16 & NKS & $52(4 \%)$ & $45(4 \%)$ \\
17 & EEE16 & $261(21 \%)$ & $0(0 \%)$ \\
\hline
\end{tabular}

ese grid points ( $\sim 141$ points) of domain 2 for 84 runs, using the above rain gauge observations. The sample size $N$ is approximately 10000 for each evaluation.

\section{a. Individual members}

The ETSs and bias scores of the 12-24-h rainfall forecasts were calculated at three different rainfall thresholds $(2.5,10$, and $25 \mathrm{~mm})$ for all 16 individual members (Fig. 8). In addition, we computed differences of ETSs between individual members and applied the resampling method of Hamill (1999) to test whether the differences reach the $90 \%$ significance level. The results are shown in the rightmost column in Table 3. A positive (negative) difference indicates that the first member performed better (worse) than the second member. Figure 8 shows that the ETSs were around 0.2 at the 2.5-mm threshold and decreased as rain thresholds increased. With the same ICs used, the members using the Grell CPS in general had higher ETSs than those using the Kain-Fritsch CPS. This was especially true at the larger thresholds of 10 and $25 \mathrm{~mm}$. It is further noted, at these two thresholds, that the members with the GFS ICs and the Grell CPS (No. 1-4) performed noticeably better than other combinations. These were clearly demonstrated in the IC and CPS groups in Table 3. Comparisons among the four MSs show that the mixed-phase MS in general gave good ETSs in the rainfall simulation, and the Goddard MS also performed well, except at the $25-\mathrm{mm}$ threshold. The third and fourth groups in Table 3 supported the above statement with good ratios of positive differences and by passing the $90 \%$ significance level. Given the low ratio of reaching the $90 \%$ significance level for the HTRW fields, the higher ratio here suggests that using different MSs has more impact on the prediction of rain than that of other meteorological variables. The bias scores show that all 


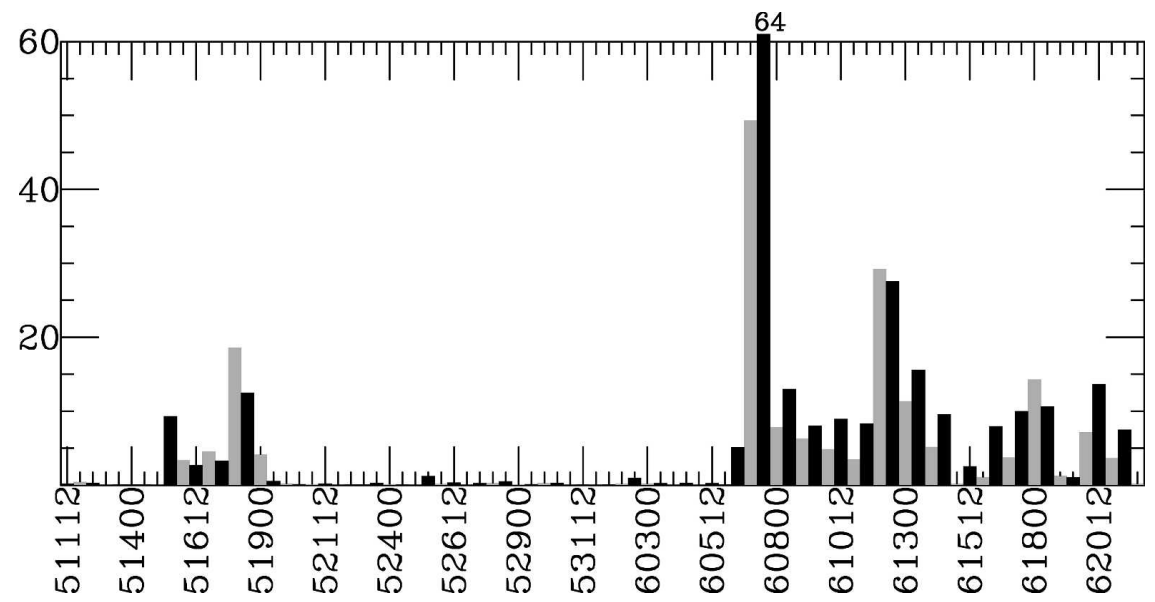

FIG. 7. The 12-h accumulated precipitation averaged for the 342 rain gauge stations in Taiwan. Ending times are from 1200 UTC 11 May (denoted by 51112 in the abscissa) to 0000 UTC 22 Jun 2003 at a 12-h interval. The bars in black denote rainfall accumulated from 0000 to 1200 UTC (daytime, 0800-2000 LST), while those in gray represent rainfall accumulated from 1200 to 0000 UTC (nighttime, 2000-0800 LST).

16 members underforecasted rainfall and that the problem became more exacerbated as rainfall thresholds increased.

\section{b. Ensemble means}

We also examined the performance of ensemble mean precipitation forecasts at $12-24 \mathrm{~h}$ by verifying the
13 means described in Table 2. The first four ensemble means in Fig. 9 show that GGE4 had higher ETSs than GKE4, and NGE4 higher than NKE4. This indicates again that the Grell CPS outperformed the KainFritsch CPS for rainfall forecasts in Taiwan. A similar conclusion can be obtained from comparisons between EGE8 and EKE8. It is also found that ensemble means

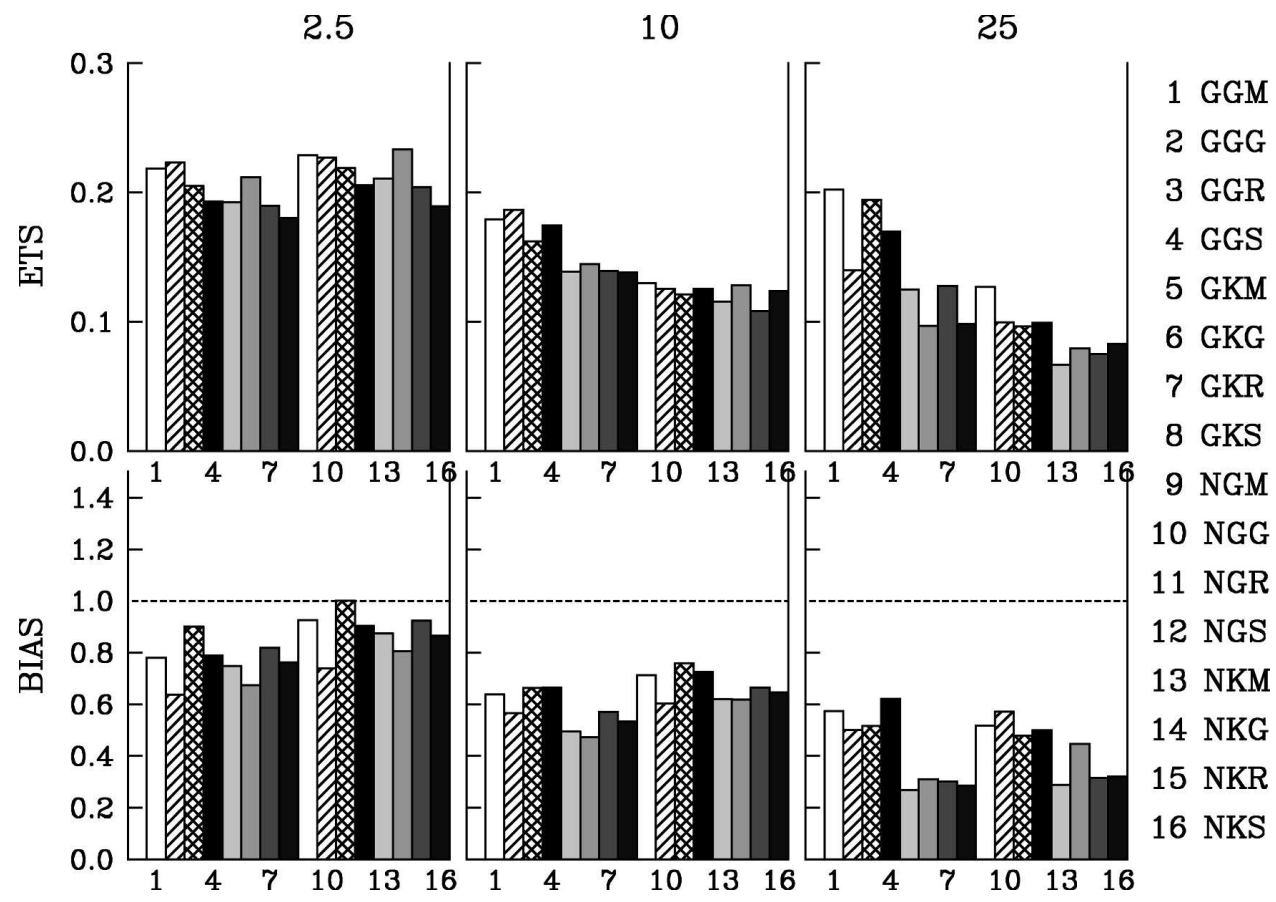

FIG. 8. The ETS and bias scores of 12-24-h precipitation forecasts of the 16 individual members at 2.5-, $10-$, and $25-\mathrm{mm}$ rainfall thresholds. Verification was done using observations at rain gauge stations in Taiwan. 


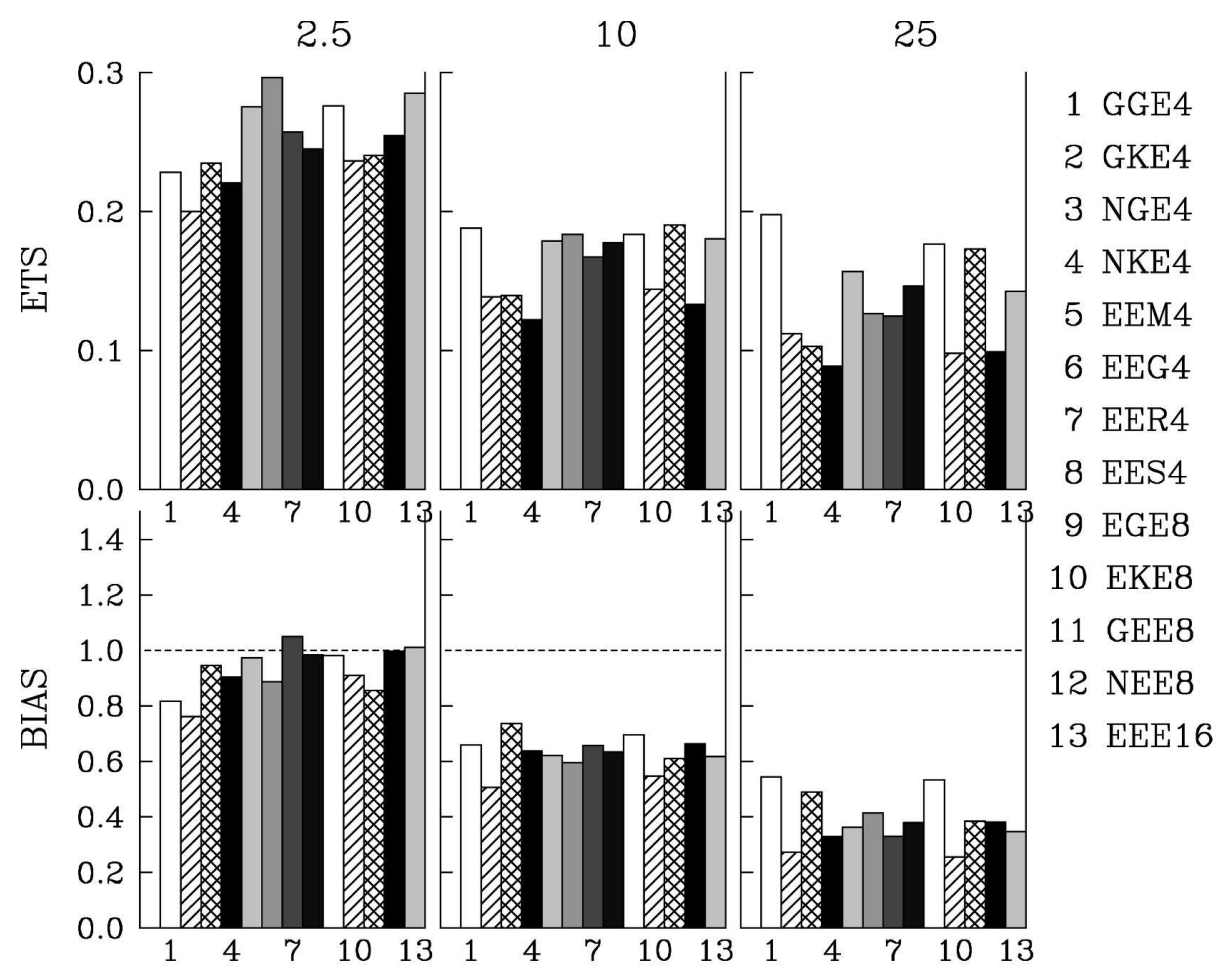

FIG. 9. Same as in Fig. 8 but for the 13 ensemble means listed in Table 2.

with the GFS ICs (e.g., GEE8) had higher ETSs than those with the NFS ICs (e.g., NEE8), except at the smallest threshold $(2.5 \mathrm{~mm})$. The fifth-eighth ensemble means show that EEG4 had the highest ETSs among the four means, except at the 25 -mm threshold. This indicates that the Goddard MS had the best skill among the four MSs to forecast rainfall, but the amount was underestimated when rainfall was heavy. The mixed-phase MS also had higher ETSs compared with the other two MSs, especially at the $25-\mathrm{mm}$ threshold. The above comparisons between different ICs, CPSs, and MSs were clearly evidenced in the rightmost column of Table 4. Figure 9 also shows that the ETSs of the all-member ensemble mean, EEE16, were around or above the ETS averages of the ensemble means that comprise all 16 members (e.g., GEE8 and NEE8). This reveals the advantage of using more members for an ensemble mean. The advantage, however, decreased as rainfall thresholds increased. Many studies (e.g., Du et al. 1997) have indicated that ensemble averaging tends to overestimate light rain and underestimate heavy rain. In our case, bias scores show that the ensemble mean performed well at the $2.5-\mathrm{mm}$ threshold and underestimated rainfall toward larger thresholds.

\section{Discussion}

There were differences, as observed from sections 3 and 4 , between the verifications of the HTRW fields and precipitation in terms of performance among different ICs, CPSs, and MSs. For forecasts of most of the HTRW fields in domain 2, the members with the KainFritsch CPS performed better than with the Grell CPS, the members with the NFS ICs did better than with the GFS ICs, and the members with the mixed-phase MS outperformed the other three MSs. The rainfall forecasts in the Taiwan area showed similar results in terms of the performance among the four MSs; that is, the mixed-phase MS had relatively high ETSs. However, the performance of rainfall forecasts between the two CPSs and between the two ICs were opposite to that of the HTRW forecasts. A possible reason is that because precipitation forecasts involve more complex physical processes, their skill may not necessarily be consistent with that of all the HTRW field forecasts at all levels. For example, rainfall forecasts could be more related to the forecast of $\mathrm{RH}$ at the low level (e.g., $850 \mathrm{mb}$ ) in which the Grell CPS slightly outperformed the KainFritsch CPS (Fig. 6). Furthermore, precipitation forecasts show that the ETS of NEE8 was slightly higher 
TABLE 6. The average of ensemble means (RMSE or ETS of ensemble means are averaged). The naming scheme is similar to that used in Table 2 except that the letter A is used to replace a column when all possible ensemble means corresponding to that column are used in computing the average.

\begin{tabular}{cll}
\hline \hline No. & Name & \\
\hline 1 & AAA1 $*$ & All 16 single members \\
2 & EAA2 & Eight two-member ensemble means that vary ICs \\
3 & AEA2 & Eight two-member ensemble means that vary CPSs \\
4 & AAE4 & Four four-member ensemble means that vary MSs; i.e., (GGE4 + NGE4 + GKE4 + NKE4)/4 \\
5 & EEA4 & Four four-member ensemble means that vary ICs and CPSs; i.e., (EEM4 + EEG4 + EER4 + EES4)/4 \\
6 & EAE8 & Two eight-member ensemble means that vary ICs and MSs; i.e., (EGE8 + EKE8) $/ 2$ \\
7 & AEE8 & Two eight-member ensemble means that vary CPSs and MSs; i.e., (GEE8 + NEE8) $/ 2$ \\
8 & EEE16 & Same as in Table 2 (no average is taken) \\
\hline
\end{tabular}

* This is an exception. AAA1 is not an average of ensemble means, but an average of RMSE/ETS of all 16 individual members.

than that of GEE8 at the 2.5-mm threshold, which was consistent with the forecasts of most of the HTRW fields. This suggests that the members with the NFS ICs performed better than those with the GFS ICs in determining whether rain would or would not occur, but when larger rainfall occurred, their skills reversed.

In sections 3 and 4, by comparing the forecast skills among the ensemble means, we found that the ensemble mean forecasts exhibited greater skill than the individual members that compose the ensemble. However, the comparisons were not quite fair because they were made based on different numbers of ensemble members. Therefore, in order to perform a more fair evaluation of the relative contribution of different ICs and physics packages to the ensemble mean, the scores (RMSE or ETS) of the ensemble means are further averaged into the groups shown in Table 6 . The naming scheme used in Table 6 is similar to that in Table 2, except that the letter $\mathrm{A}$ is used to replace a column when the scores of all possible ensemble means corresponding to that column are used in the average. For example, AEE8, taking an average of scores of GEE8 and NEE8, represents the average performance of the eight-member ensemble means that contain members using different CPSs and MSs; AAE4 is a measure of the average skill of the four-member ensemble means (GGE4, NGE4, GKE4, and NKE4) that have members with differing MSs; EAA2 denotes the average performance of all two-member ensemble means that have members with different ICs, and so on. There are two exceptions in Table 6: EEE16 is simply the 16-member ensemble mean forecast discussed previously and, thus, no average is taken; AAA1, denoting the average performance of individual members, is obtained by averaging the scores of the 16 individual members. In this method the eight combinations take into account all 16 members in the average. The only differences among them are the numbers and elements of the ensemble members. In other words, we are evaluating, on a more equitable basis, the average performance of ensemble mean forecasts.

Figure 10 shows RMSEs of the HTRW fields for the eight average combinations listed in Table 6. Obviously, AAA1 had the highest RMSEs for all variables at all levels. This indicates that on average an ensemble mean, no matter how many members it contains, can produce better forecasts (lower RMSE) than the average of individual members. EEE16, which consists of all members in the ensemble, possessed the lowest RMSEs among the eight combinations. This implies that on average using more diverse members (with perturbed physics and ICs) in an ensemble can produce better forecasts from the available simulations.

The quality of an ensemble mean depends not only on the amount of members, but also on what members it chooses. As seen from most of the variables in Fig. 10, RMSEs of EAA2 were smaller than those of AEA2, which were in turn smaller than those of AAE4. The only exceptions were RMSEs of temperature at low levels. This suggests that an ensemble mean of IC differing members performed better than that of CPS differing, and an ensemble mean of MS differing members performed the worst. Because the first two combinations are the averages of the two-member ensembles and the last is the average of the four-member ensembles, it is clear that the choice of members is more important than the number of members in determining the performance of ensemble means. A similar scenario was observed for EEA4, EAE8, and AEE8. EEA4 is the average of the four-member ensembles that contain members of differing ICs and CPS, EAE8 is the average of the eight-member ensembles that have members of varying ICs and MS, and AEE8 is similar to EAE8 but with differing CPS and MS. Because IC varying is common between the first two combinations, comparisons between them imply that ensemble means with CPS-varying members outperformed those with MSvarying members. Two other similar comparisons could 


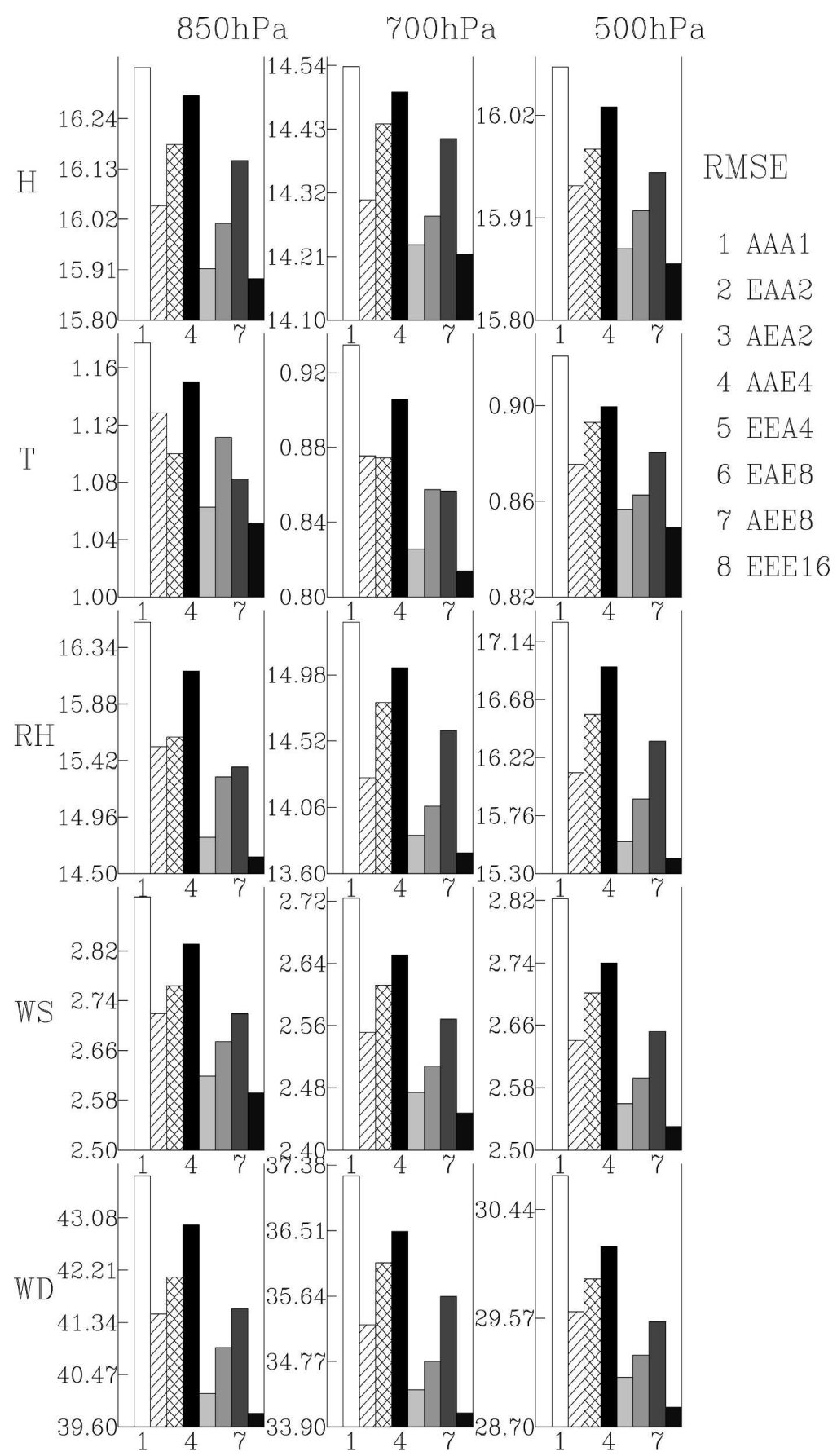

FIG. 10. Same as in Fig. 3 but for the eight average combinations listed in Table 6 .

be made between EEA4 and EAE8, and between EEA4 and AEE8. Combining the three provided further evidence of the aforementioned conclusion that the best choice of composing an ensemble is to vary the ICs, then to vary CPS, and, last, to vary MS.

The above results are further examined by computing RMSE differences between EEE16 and other en- semble means or individual members. Table 7 shows that, for the HTRW fields, most of the differences were negative, and some were large enough to reach the $90 \%$ significance level. The ratio of reaching the $90 \%$ significance level increased from the difference between EEE16 and the ensemble means with more members to that with the individual members (group 7 to group 1). 
TABLE 7. Same as in Table 3 but for differences between EEE16 and other ensemble means or individual members. See Table 6 for acronyms.

\begin{tabular}{|c|c|c|c|c|c|c|c|}
\hline & Group No.* & $H$ & $T$ & RH & WS & WD & Rain \\
\hline EEE16 - AAA1 & 1 & $15(6) / 33(12)$ & $4(0) / 44(35)$ & $0 / 48(43)$ & $0 / 48(47)$ & $0 / 48(27)$ & $42(29) / 6(2)$ \\
\hline EEE16 - EAA2 & 2 & $10(4) / 14(5)$ & $5(0) / 19(9)$ & $0 / 24(11)$ & $0 / 24(7)$ & $1(0) / 23(2)$ & $18(11) / 6(1)$ \\
\hline EEE16 - AEA2 & 3 & $7(0) / 17(0)$ & $0 / 24(13)$ & $0 / 24(14)$ & $0 / 24(19)$ & $0 / 24(4)$ & $17(14) / 7(1)$ \\
\hline EEE16 - AAE4 & 4 & $5(1) / 7(2)$ & $1(0) / 11(8)$ & $0 / 12(11)$ & $0 / 12(11)$ & $0 / 12(5)$ & $10(7) / 2(0)$ \\
\hline EEE16 - EEA4 & 5 & $5(0) / 7(0)$ & $1(0) / 11(0)$ & $2(0) / 10(0)$ & $1(0) / 11(0)$ & $2(0) / 10(0)$ & $6(2) / 6(0)$ \\
\hline EEE16 - EAE8 & 6 & $3(1) / 3(1)$ & $1(1) / 5(2)$ & $0 / 6(0)$ & $0 / 6(0)$ & $1(0) / 5(0)$ & $4(1) / 2(1)$ \\
\hline EEE16 - AEE8 & 7 & $3(0) / 3(0)$ & $0 / 6(2)$ & $0 / 6(3)$ & $0 / 6(2)$ & $0 / 6(1)$ & $4(4) / 2(0)$ \\
\hline
\end{tabular}

* Pairs of ensemble means used in the corresponding group:

1) EEE16 minus any of the 16 individual members (16 pairs $\times 3$ levels/thresholds);

2) EEE16 minus any of the 8 ensemble means used in EAA2 ( 8 pairs $\times 3$ levels/thresholds);

3) EEE16 minus any of the 8 ensemble means used in AEA2 ( 8 pairs $\times 3$ levels/thresholds);

4) EEE16 minus any of the 4 ensemble means used in AAE4 (4 pairs $\times 3$ levels/thresholds);

5) EEE16 minus any of the 4 ensemble means used in EEA4 (4 pairs $\times 3$ levels/thresholds);

6) EEE16 minus any of the 2 ensemble means used in EAE8 ( 2 pairs $\times 3$ levels/thresholds); and

7) EEE16 minus any of the 2 ensemble means used in AEE8 ( 2 pairs $\times 3$ levels/thresholds).

This indicates that EEE16 was the best among all ensemble means, and was significantly better than the individual members.

Figure 11 presents ETSs of 12-24-h precipitation forecasts for the eight average combinations. The scores show a similar pattern as in Fig. 10 of the relative performance among the eight combinations. For example, EEE16 had the best skill and AAA1 had the worst in rainfall forecasts, and so on. This was more profound at the smaller rainfall thresholds than at the larger ones, indicating that the benefit of an ensemble mean decreases as the rainfall amount increases. The rightmost column in Table 7 further shows the significance of the above result. Combining Fig. 10, Fig. 11, and Table 7, we can draw three conclusions. First, on average, an ensemble mean, no matter how many members it contains, has an advantage over forecasts from an individual member. Second, among the three possible varying elements (ICs, CPS, and MS) used to compose an ensemble mean, the ensemble that contains members with all three elements varying performed the best, the ensemble that has members with two elements varying was second best, and the ensemble that includes members with only one element differing was the worst. Last, the first choice for composing an ensemble is to use perturbed ICs, followed by perturbed CPS, and then perturbed MS.

\section{Summary and conclusions}

This paper presents an evaluation study, in terms of forecasts of geopotential height, temperature, relative humidity, wind speed, wind direction, and precipitation, for a real-time mesoscale ensemble prediction system in the Taiwan area during the 2003 mei-yu season. The ensemble system, using the MM5 as a forecast model, consisting of 16 members that vary in a full spectrum among two cumulus schemes (the Grell and KainFritsch CPSs), four microphysics schemes (the mixed phase, Goddard, Reisner II, and Schultz MSs), and two initial conditions (the GFS and NFS ICs, both produced by the CWB of Taiwan).

For verification of geopotential height, temperature, relative humidity, wind speed, and wind direction (HTRW), it is found that the members using the KainFritsch CPS had mostly lower RMSEs compared with those using the Grell CPS. The members that used the mixed-phase MS exhibited the smallest RMSEs among the four MSs. The members that used the NFS ICs, in general, had smaller errors than those using the GFS ICs. It is therefore suggested that the Kain-Fritsch CPS, the mixed-phase MS, and the NFS ICs were the

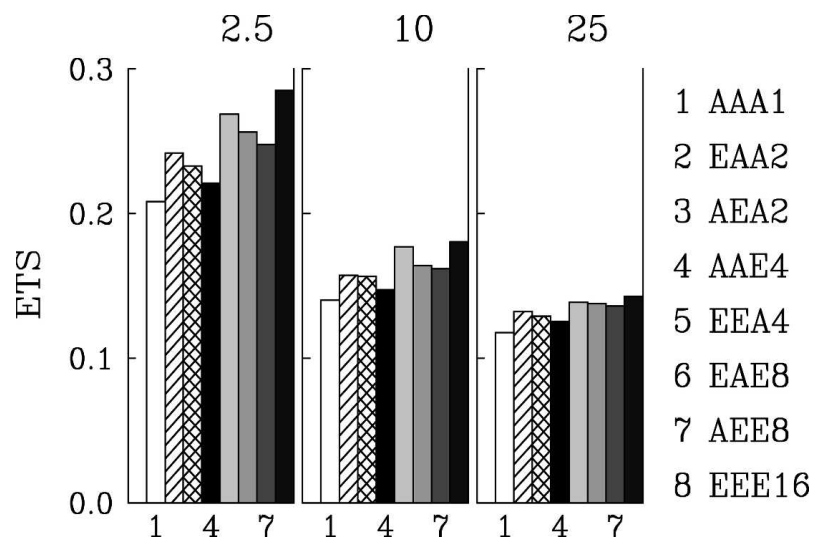

FIG. 11. Same as in Fig. 8 but for ETS of the eight average combinations listed in Table 6. 
best combination for MM5 simulations in the Taiwan area during a mei-yu season when the accuracy of the HTRW fields is of concern. From the mean error, we found that the MM5 tended to overpredict geopotential height and underpredict wind speed, and have cold and dry biases in this region. Correlation coefficients show that geopotential height predictions had the highest correlation with the analyses among the five meteorological fields.

From the ETSs and the bias scores of the 12-24-h accumulated rainfall at three different rainfall thresholds $(2.5,10$, and $25 \mathrm{~mm})$, in general, we found that the members using the Grell CPS had higher ETSs than those using the Kain-Fritsch CPS, that the members with the GFS ICs performed better than those with the NFS ICs, and that the mixed-phase and the Goddard MSs gave good ETSs in the rainfall simulation. The findings of the best physics combination with the Grell CPS and the mixed-phase MS are consistent with the studies of Chien et al. (2002) and Chien and Jou (2004). The bias scores show that all 16 members underforecasted rainfall, and that the problem became more exacerbated as rainfall thresholds increased.

The above conclusions are more evident from the RMSEs and ETSs of the 13 ensemble mean forecasts. There are, however, some noticeable differences between the verifications of the HTRW fields and precipitation. A possible reason is that because precipitation forecasts involve more complex physical processes, their skill may not necessarily be consistent with that of all the HTRW field forecasts at all levels. In fact, rainfall forecasts were more related to the forecast of $\mathrm{RH}$ at low levels in which the Grell CPS slightly outperformed the Kain-Fritsch CPS. Furthermore, it is suggested that the members with the NFS ICs performed better than those with the GFS ICs in determining whether rain would occur, but when larger rainfall occurred, their skills reversed.

The scores (RMSE or ETS) of the ensemble means are further averaged into groups to represent the average performance of the ensemble means. The results are summarized in three conclusions. First, an ensemble mean, no matter how many members it contains, on average has an advantage over forecasts from individual members. Second, among the three possible varying elements (ICs, CPS, and MS) used to compose an ensemble mean, the ensemble that contains members with all three elements varying performed the best, the ensemble that has members with two varying was second best, and the ensemble that includes members with only one element differing was the worst. Finally, the first choice for composing an ensemble is to use perturbed ICs, followed by perturbed CPS, and the last choice is to use perturbed MS.

Acknowledgments. This research was supported by National Science Council of Taiwan (Grants NSC922625-Z-003-002, NSC92-2111-M-003-001-AP2, and NSC95-2111-M-002-018-AP2). We thank the Central Weather Bureau for providing numerical and observational data used in this study. We are also grateful to our colleagues, Pay-Liam Lin, Jing-Shan Hong, LinFon Hsiao, Win-Jing Chang, and Fon-Chin Wang for their collaborative efforts during the experiments. Use of the MM5 was made possible by the Mesoscale and Microscale Meteorological Division of the National Center for Atmospheric Research. Helpful comments provided by the anonymous reviewers are highly appreciated. Our gratitude also goes to the Academic Paper Editing Clinic, NTNU.

\section{REFERENCES}

Andersson, E., and Coauthors, 1998: The ECMWF implementation of three-dimensional variational assimilation (3D-Var). III: Experimental results. Quart. J. Roy. Meteor. Soc., 124, 1831-1860.

Buizza, R., and T. N. Palmer, 1995: The singular-vector structure of the atmospheric general circulation. J. Atmos. Sci., 52, 1434-1456.

Chen, G. T.-J., and C.-Y. Liang, 1992: A midlevel vortex observed in the Taiwan Area Mesoscale Experiment (TAMEX). J. Meteor. Soc. Japan, 70, 25-41.

Chen, Y.-L., and N. B.-F. Hui, 1990: Analysis of a shallow front during the Taiwan Area Mesoscale Experiment. Mon. Wea. Rev., 118, 2649-2667.

Chien, F.-C., and B. J.-D. Jou, 2004: MM5 ensemble mean precipitation forecasts in the Taiwan area for three mei-yu seasons. Wea. Forecasting, 19, 735-750.

_, Y.-H. Kuo, and M.-J. Yang, 2002: Precipitation forecasts of the MM5 in Taiwan area during the 1998 mei-yu season. Wea. Forecasting, 17, 739-754.

Du, J., S. L. Mullen, and F. Sanders, 1997: Short-range ensemble forecasting of quantitative precipitation. Mon. Wea. Rev., 125, 2427-2459.

Ebert, E. E., 2001: Ability of a poor man's ensemble to predict the probability and distribution of precipitation. Mon. Wea. Rev., 129, 2461-2480.

Epstein, E. S., 1969: Stochastic dynamic prediction. Tellus, 21, 739-759.

Grell, G. A., J. Dudhia, and D. R. Stauffer, 1994: A description of the fifth-generation Penn State/NCAR Mesoscale Model (MM5). NCAR Tech. Note NCAR/TN-398+STR, 138 pp.

Grimit, E. P., and C. F. Mass, 2002: Initial results of a mesoscale short-range ensemble forecasting system over the Pacific Northwest. Wea. Forecasting, 17, 192-205.

Hamill, T. M., 1999: Hypothesis tests for evaluating numerical precipitation forecasts. Wea. Forecasting, 14, 155-167.

Hong, S.-Y., and H.-L. Pan, 1996: Nonlocal boundary layer vertical diffusion in a medium-range forecast model. Mon. Wea. Rev., 124, 2322-2339.

Houtekamer, P. L., and H. L. Mitchell, 1998: Data assimilation 
using an ensemble Kalman filter technique. Mon. Wea. Rev., 126, 796-811.

—, L. Lefaiver, J. Derome, H. Ritchie, and H. L. Mitchell, 1996: A system simulation approach to ensemble prediction. Mon. Wea. Rev., 124, 1225-1242.

Kain, J. S., and J. M. Fritsch, 1992: The role of the convective "trigger function" in numerical forecasts of mesoscale convective systems. Meteor. Atmos. Phys., 49, 93-106.

Kuo, Y.-H., and G. T.-J. Chen, 1990: The Taiwan Area Mesoscale Experiment (TAMEX): An overview. Bull. Amer. Meteor. Soc., 71, 488-503.

Leith, C. E., 1974: Theoretical skill of Monte Carlo forecasts. Mon. Wea. Rev., 102, 409-418.

Leou, T.-M., and C.-S. Liou, 2000: The Central Mountain Range of Taiwan Island in Central Weather Bureau non-hydrostatic limited area model. Preprints, Ninth Conf. on Mountain Meteorology, Aspen, CO, Amer. Meteor. Soc., 367-368.

Li, J., Y.-L. Chen, and W.-C. Lee, 1997: Analysis of a heavy rainfall event during TAMEX. Mon. Wea. Rev., 125, 1060-1081.

Lin, Y.-J., R. W. Pasken, and H.-W. Chang, 1992: The structure of a subtropical prefrontal convective rainband. Part I: Mesoscale kinematic structure determined from dual-Doppler measurements. Mon. Wea. Rev., 120, 1816-1836.

Liou, C. S., and Coauthors, 1997: The second-generation Global Forecast System at the Central Weather Bureau in Taiwan. Wea. Forecasting, 12, 653-663.

Lorenz, E. N., 1963: Deterministic nonperiodic flow. J. Atmos. Sci., 20, 130-141.

Molteni, F., R. Buizza, T. N. Palmer, and T. Petroliagis, 1996: The ECMWF Ensemble Prediction System: Methodology and validation. Quart. J. Roy. Meteor. Soc., 122, 73-119.

Mullen, S. L., and D. P. Baumhefner, 1988: Sensitivity to numerical simulations of explosive oceanic cyclogenesis to changes in physical parameterizations. Mon. Wea. Rev., 116, 22892329.

Ray, P. S., A. Robinson, and Y. Lin, 1991: Radar analysis of a TAMEX frontal system. Mon. Wea. Rev., 119, 2519-2539.

Schaefer, J. T., 1990: The critical success index as indicator of warning skill. Wea. Forecasting, 5, 570-575.

Stensrud, D. J., and J. M. Fritsch, 1994a: Mesoscale convective systems in weakly forced large-scale environments. Part II: Generation of a mesoscale initial condition. Mon. Wea. Rev., 122, 2068-2083.

— and _ 1994b: Mesoscale convective systems in weakly forced large-scale environments. Part III: Numerical simulations and implications for operational forecasting. Mon. Wea. Rev., 122, 2084-2104.

- and N. Yussouf, 2003: Short-range ensemble predictions of 2-m temperature and dewpoint temperature over New England. Mon. Wea. Rev., 131, 2510-2524.

— , H. E. Brooks, J. Du, M. S. Tracton, and E. Rogers, 1999: Using ensembles for short-range forecasting. Mon. Wea. Rev., 127, 433-446.

_ - J.-W. Bao, and T. T. Warner, 2000: Using initial condition and model physics perturbations in short-range ensemble simulations of mesoscale convective systems. Mon. Wea. Rev., 128, 2077-2107.

Toth, Z., and E. Kalnay, 1993: Ensemble forecasting at NMC: The generation of perturbations. Bull. Amer. Meteor. Soc., 74, 2317-2330.

Tracton, S., and E. Kalnay, 1993: Ensemble forecasting at NMC: Operational implementation. Wea. Forecasting, 8, 379-398.

Wang, W., and N. L. Seaman, 1997: A comparison study of convective parameterization schemes in a mesoscale model. Mon. Wea. Rev., 125, 252-278.

Wilks, D. S., 1995: Statistical Methods in the Atmospheric Sciences. Academic Press, 467 pp. 